\title{
Research on the professional ethics issues of CPA in China
}

\author{
Xuejun Zhang, Bin Liu \\ School of Economics and Management, Jiangsu University of Science and Technology, Zhenjiang, \\ Jiangsu, China
}

\begin{abstract}
Since the 1990s, auditing collusion cases have occured frequently, reducing the integrity degree of CPA. Of all reasons, we should pay attention to professional ethics issues most. Because of professional ethics issues, the public have lost confidence in the industry of CPA. The industry of CPA is faced with serious crisis. In the circumstance, this paper researched professional ethics issues of CPA. Firstly, it explained the connotation of professional ethics, emphasized the importance. Secondly, through real cases, this paper analyzed the present situation of professional ethics of CPA, explained the lack of professional ethics. Finally, for solving the problem, this paper proposed the countermeasures to enhance the standards of professional ethics of CPA from the external and internal practice environment.
\end{abstract}

Keywords. CPA; Professional ethics; Lack; Measures

\section{Introduction}

With the development of economy, the industry of CPA as an economic services part, plays an important role in maintaining the order of market economy and facilitating a healthy and orderly development of the market. However, a series of auditing collusion cases damaged the image of CPA (Muxuan, 2012), people began to realise the lack of professional ethics. The situation became more serious. Therefore, it is necessary to research professional ethics issues of CPA .

\section{Connotation of professional ethics of CPA}

\subsection{Conception}

On July 1, 2010, the code of the professional ethics of CPA was carried out. It defined professional ethics of CPA as a general term of professional morality, professional discipline, professional competence and professional responsibility (Hongyu, 2003). It required that CPA should abide by the principle of integrity, objectivity and justice. Faced with auditing business, CPA should maintain independence. Furthermore, CPA must have enough professional competence.

\subsection{Characteristics}




\subsubsection{Uncertainty}

Although CPA is responsible for their clients, the clients are not the only beneficiaries. Other stakeholders also need the information from CPA. Therefore, the beneficiaries are uncertain.

\subsubsection{Publicness}

Different from doctors and lawyers, CPA is responsible for society. Their auditing reports are open to the public. Therefore, CPA is supervised by the public. Only are the public pleased with auditing results, they will believe CPA.

\subsubsection{Asymmetry}

Auditing reports are used by many stakeholders, including managers, shareholders, creditors, governments and the public. However, CPA only gets payments from one of the stakeholders. CPA is faced with the evaluation from whole society. Therefore, there is an asymmetry between payments and risk.

\subsection{Importance}

Professional ethics are the foundation of the industry of CPA, it determines the development of the industry of CPA. It can remind CPA of social responsibility. To some extent, it can guarantee the quality of auditing reports. Without professional ethics, CPA may choose unethical behaviour, resulting in auditing failures. Auditing failures can cause serious consequences. Firstly, investors will suffer big losses. Secondly, it can damage the image of CPA. As a result, CPA will lose their clients, and even be involved in litigation cases. Lastly, auditing failures will have an impact on stock markets, seriously affecting investors on the attitude and confidence in the stock market.

\section{Current situation of professional ethics of CPA}

\subsection{Shengjing Shanhe financial fraud case}

Shengjing Shanhe is a Biotechnology Co., Ltd in Hunan province. It mainly produces yellow rice wine. On December 8, 2010, it issued 17 million shares through online and offline, and each share is 34.2 yuan. As a result, it successfully raised 580 million yuan of funds. For Shengjing Shanhe, December 17, 2010 was a significant day for listing. However, Shengjing Shanhe was suspected of being involved in IPO fraud and with an emergency stop half an hour before listing. Then, it was investigated by the CSRC(China Securities Regulatory Commission). According to the survey, from 2006 to 2008, annual sales revenues of above-scale enterprises in the industry of yellow rice wine are 5.678 billion yuan, 7.310 billion yuan and 7.462 billion yuan, respectively. Annual sales revenues of Shengjing Shanhe are 0.036 billion yuan, 0.087 billion yuan and 0.123 billion yuan, respectively (Haili, 2013). More details are shown in table1.

From table1, it can be seen that market share of Shengjing Shanhe in total industry is very low. However, it's gross profit rate was 10 percentage points higher than average level. Shengjing Shanhe inflated revenues and fabricated stocks to achieve this goal. At last, it was refused by CSRC (China Securities Regulatory Commission). Accounting firm of Zhong Shen is responsible for auditing Shengjing Shanhe. Faced with obvious financial frauds, the CPAs didn't find the mistakes. Without sufficient evidence, the CPAs still issued false opinions. They completely ignored professional ethics.

Table 1. Proportion of Shengjing Shanhe's sales revenues in total industry Unit: billion yuan 


\begin{tabular}{l|l|l|l}
\hline & Sales revenues of Shengjing Shanhe & Sales revenues of total industry & Proportion (\%) \\
\hline $\mathbf{2 0 0 6}$ & 0.036 & 5.678 & 0.64 \\
\hline $\mathbf{2 0 0 7}$ & 0.087 & 7.310 & 1.19 \\
\hline $\mathbf{2 0 0 8}$ & 0.123 & 7.462 & 1.65 \\
\hline
\end{tabular}

Data from: China Alcoholic Drinks Industry Association and financial reports of each enterprise

\subsection{Wanfu Shengke financial fraud case}

In September 2011, Wanfu Shengke Co., Ltd listed successfully. However, less than a year, it was investigated by CSRC (China Securities Regulatory Commission). According to the survey, from 2008 to 2011, Wanfu Shengke inflated incomes 740 million yuan, and inflated pure profits about 160 million yuan. The ways of financial frauds were a lot. For example, inflating customers and fabricating contracts. Semi-annual report of 2012 showed that, Wanfu Shengke inflated revenues 188 million yuan. Wang yue and Guohua Huang from accounting firm of Zhong Lei were responsible for auditing Wanfu Shengke. Like other auditing collusion cases, they issued false auditing reports without sufficient evidence. Their unethical behaviour had caused a bad effect on society.

\subsection{New Land financial fraud case}

New Land biotechnology Co.,Ltd was a unknown enterprise, which produced tea-oil camellia. In May 2012, New Land's application for IPO was approved by CSRC(China Securities Regulatory Commission). However, less than two months, it was investigated by CSRC(China Securities Regulatory Commission). The result showed that, it inflated profits and reduced costs to intend to achieve their goal of listing. Faced with the obvious mistakes, Haibin wang and Chunkui Liu from accounting firm of Da Hua should have found the financial fraud. After getting some profits from the managers of New Land, they issued false auditing opinions to help New Land. Their unethical behaviour had caused a bad effect on society, undermining the construction of a harmonious socialist society.

Like these auditing collusion cases, there are a lot. This paper just listed a few representative examples. These examples tell us that the lack of professional ethics is very serious.

\section{Reasons for the lack of professional ethics}

\subsection{Lack of effective code of professional ethics}

In order to make CPAs undertake the sacred responsibility earnestly, On July 1,2010, CICPA (The Chinese Institute of Certified Public Accountants) carried out The code of the professional ethics of CPA. The code should have improved the standards of professional ethics of CPA profession. In fact, more and more financial frauds and auditing collusion cases occured. The reason for the phenomenon was that the code of professional ethics was uneffective. An effective code of professional ethics should include basic norm of professional ethics, detailed norm of professional ethics, and operation instruction of professional ethics. However, our country's code lacked of detailed norm and operation instruction. Moreover, our country's code was established on the basis of overseas. Our country's conditions were different from overseas. Therefore, professional norms of overseas weren't suited to us. In this circumstance, CPAs dared to ignore the professional ethics, and did unethical behaviour.

\subsection{Lack of effective Supervision and Punishment}


According to the law of CPA, several administrative agencies have the power to supervise the industry of CPA. More details are shown in figure 1.

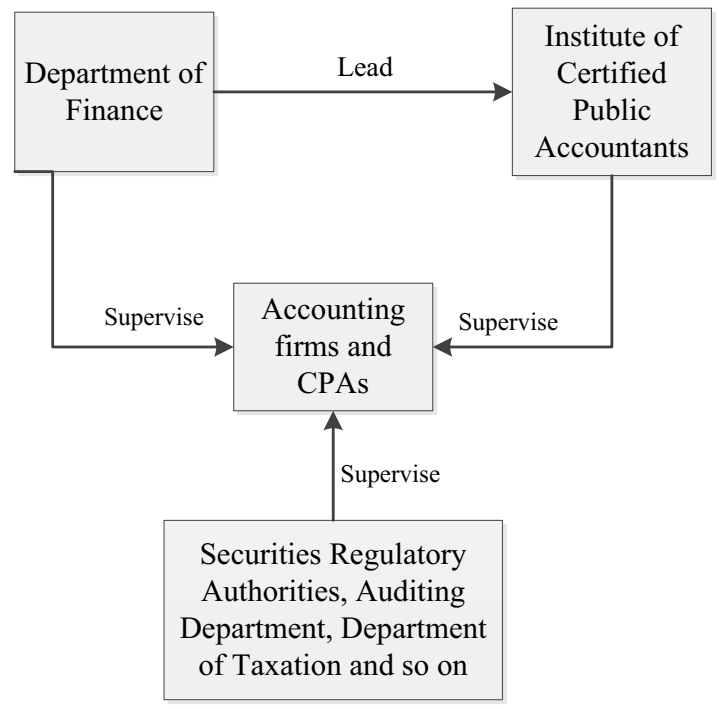

Figure 1. The new regulatory system of CPA industry

Although several agencies supervised the industry of CPA, their delimitation of power was unclear, existing functional overlap. In addition, they lacked effective communication mechanism. As a result, it resulted in a invalid supervision. Taking advantage of the loopholes of supervision system, CPA dared to ignore professional ethics. Moreover, even though their unethical behaviors were found, they weren't afraid. In china, punishments to professional ethics are light. Punishments are mainly administrative penalty. Compared with benefits from auditing frauds, the cost are very low. In the circumstance, CPA dared to ignore professional ethics (Shana, 2007).

\subsection{Lack of effective internal control system}

In China, the proportion that chairman and president is the same person is very high. The phenomenon damaged internal control system seriously. On the one hand, CPA is responsible for investors, on the other hand, CPA gets payments from managers of the audited enterprises. In this circumstance, CPA encounters dilemmas. If CPA doesn't obey the managers, he will be dismissed. In order to survive, CPA ignores the professional ethics, and chooses to issue false auditing opinions.

\section{Strategies}

\subsection{Improve external practice environment of CPA}

Firstly, CICPA (The Chinese Institute of Certified Public Accountants) should carry out detailed norms, operation instructions as soon as possible. Secondly, to maximise the function of ICPA (the institutes of Certified Public Accountants), it is necessary to reform function of financial departments. It should supervise ICPA instead of leading (Yanjing, 2013). Auditing departments should guide ICPA auditing business instead of supervising. Departments of industry and commerce, and taxation should assist CPA actively within their power. In addition, the supervision departments should strengthen communication to deal with professional ethical issues. Thirdly, 
Civil compensation of mechanism should be introduced. Criminal punishment can be adopted if necessary. When costs of punishments exceed benefits from auditing frauds, CPA will obey the code of professional ethics.

\subsection{Improve internal practice environment of CPA}

In order to improve independence of CPA, ICPA (the institutes of Certified Public Accountants) should establish a non-profit agency as an intermediary to supervise the transaction between accounting firm and audited enterprise (Fuqing, 2011). The agency should be composed of professionals. Before being audited, audited enterprise gives auditing fees to the agency. At the end of auditing, the agency should review the auditing report. If there is no error in the report, accounting firms will get the fees from the agency. By this way, we can improve the independence of CPA, reducing the risk of auditing failure. Furthermore, it is necessary to propagandize integrity in whole society. It can make CPA aware of the importance of professional ethics.

\section{References}

1. Muxuan Du.Research on professional ethics of certified public accountants in our country [D]. Jiangsu University of science and technology, 2012.

2. Hongyu Wang.Talk about professional ethics construction of certified public accountants in china [J].Business research, 2003(9): 76-77.

3. Haili Li.Case analysis and research about IPO financial fraud of Sheng Jing Shan He [D]. Lanzhou University, 2013.

4. Shana.Strengthen moral construction of certified public accountant from the perspective of the government [J]. Macroeconomic Research, 2007(10): 47-50.

5. Yanjing.Perfect industry regulatory system research of certified public accountants in china [J]. Journal of Minjiang University, 2013, 34(4): 33-37.

6. Fuqing Liu.a brief analysis of professional ethics of certified public accountants [J]. Communication of Finance and accounting:comprehensive edition, 2011(9): 145-146. 